\title{
Editorial comment: Hippocratic Oath and plagiarism
}

\author{
Ananias C. Diokno
}

Published online: 13 June 2010

(C) Springer Science+Business Media, B.V. 2010

Academic medicine is an option that a physician might choose as a career path. Scholarly activity that includes scientific discovery is one of the criteria of being an academician. Consequence to scientific discovery is the joy of sharing the findings with colleagues realizing that not only does it enrich the knowledge of the reader, but directly or indirectly it improves the lives of patients who could be the beneficiary of the discovery.

As a physician, we took the Hippocratic Oath which is to swear to practice medicine ethically. To quote the oath's last line: "While I continue to keep this oath unviolated, may it be granted to me to enjoy life and practice of the art, respected by all men at all times; but should I trespass and violate this oath, may the reverse be my lot."

There are many temptations to violate this oath. For an academician, the pressure of publishing in peerreviewed journals as a requirement for promotions and the peer pressure to contribute scientific knowledge for recognition are at times too strong that the weak may succumb to unethical short cuts. One easy way to shortcut is to steal one's idea and blatantly claim and publish the idea as his/her own. This is plagiarism.

Unfortunately, such an incident occurred recently in our own journal. A manuscript entitled: "Importance

A. C. Diokno $(\square)$

International Urology and Nephrology, Beaumont

Hospital, Royal Oak, MI, USA

e-mail: adiokno@beaumont.edu of Hypogonadism and Testosterone Replacement Therapy in Current Urologic Practice: A Review" was published online in this journal on 12 March 2010. Fortunately, the citation of this E-publication was immediately discovered by the original author, Wayne Hellstrom, M.D. and Craig Donatucci, M.D. (thanks to advances in information technology), who notified our editorial office. The original paper was published and presented at the American Urological Association (AUA) postgraduate course on Saturday, April 15, 2008. After investigating the complaint and discovering that the paper published online in our journal was almost $100 \%$ copy of the original course material, we immediately took the following actions:

1. Informing the plagiarizers of our finding.

2. Retracting the paper published online: (http:// www.springerlink.com/content/03k0226j207q82 $31 / ? \mathrm{p}=863 \mathrm{~cd} 1900 \mathrm{ab} 84 \mathrm{f} 86 \mathrm{a} 592 \mathrm{a} 69 \mathrm{fdfac} 788 \mathrm{~d} \&$ $\mathrm{pi}=2$ ).

3. Informing the authorities of their respective hospital and university of the plagiarization.

4. Banning the authors from publishing in our journal for 5 years.

5. Notifying the authors of the plagiarized paper of our action.

The last action we are taking is this editorial to alert all authors contemplating on submitting any manuscript in this journal that we have ZERO TOLERANCE for plagiarism. 